\title{
Efeito da redução do ponto de congelamento das massas para a produção de pães tipo forma contendo ingredientes funcionais sobre a viabilidade de células de levedura
}

\author{
R. A. ZAMBELLI ${ }^{1}$, S. C. P. de MELO ${ }^{1}$, E. C. SANTOS-JUNIOR ${ }^{1}$, L. I. F. PINTO' ${ }^{1}$, P. E. F. \\ MELO $^{1}$ e D. F. PONTES 1 . \\ ${ }^{1}$ Universidade Federal do Ceará, Departamento de Tecnologia de Alimentos. \\ E-mail para contato: Zambelli@alu.ufc.br
}

\begin{abstract}
RESUMO - O estudo teve como objetivo estudar a redução do ponto de congelamento das massas e avaliar o efeito na viabilidade de células de levedura. Foram desenvolvidas 5 formulações de pães, uma padrão, sem a adição de ingredientes funcionais e as contendo 5 e $10 \%$ de polidextrose/brócolis em pó (B1 e B2); 5 e 10\% polidextrose/açaí em pó (A1 e A2). As massas foram congeladas em freezer por até 60 dias. Foram avaliados as curvas de congelamento por 24 horas e a viabilidade celular em UFC/g. Na curva de congelamento da massa padrão foi possível observar o ponto de cristalização da água e dos solutos, esta cristalização total promoveu maior redução da viabilidade

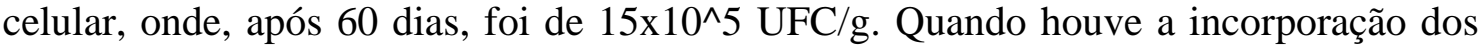
ingredientes funcionais o ponto de congelamento foi reduzido para temperaturas inferiores a $-10{ }^{\circ} \mathrm{C}$, não foi possível observar o ponto de cristalização dos solutos e isto refletiu na maior viabilidade celular, onde todas foram superiores a $55 \times 10^{\wedge} 5 \mathrm{UFC} / \mathrm{g}$.
\end{abstract}

\subsection{INTRODUÇÃO}

O congelamento e o armazenamento congelado de massas para a produção de pães, bem com o o uso do congelamento em diversas etapas da produção dos pães prejudica a qualidade dos produtos, conforme expostos por Meziani et al. (2012) e Ribotta et al. (2008). Shi et al. (2013) afirmam que o congelamento deteriora a qualidade panificável da massa de pão congelada, a viabilidade da levedura neste processo é um dos aspectos importantes, explicam que as células de levedura estão expostas à muitos estresses associados ao processo de panificação, como o congelamento e descongelamento, o ar de secagem e elevadas concentrações de soluto como sais e açúcar. As etapas que envolvem o uso de baixas temperaturas podem ocasionar graves danos para as células de levedura e diminuir a capacidade fermentativa das massas.

O uso de ingredientes funcionais em pães tipo forma, pode, além de melhorar o valor nutricional dos produtos, fornecer benefícios tecnológicos, promovendo a redução dos danos causados à estrutura do glúten e as leveduras ocasionados pelo congelamento das massas.

O presente estudo teve como objetivo estudar a obtenção de pães tipo forma com ingredientes funcionais através da tecnologia de massas congeladas, estudando o comportamento das curvas de congelamento das massas e avaliar o efeito da estocagem congelada por até 60 dias nas células viáveis de levedura. 


\subsection{METODOLOGIA}

\subsection{Delineamento Experimental}

Foram desenvolvidas formulações de pães tipo forma incorporadas com diferentes quantidades de polidextrose, açaí e brócolis em pó, conforme apresentados na tabela 1.

Tabela 1 - Formulações de pães tipo forma utilizadas no estudo da obtenção através de massas congeladas

\begin{tabular}{cccccc}
\hline Ingredientes (\%) & Padrão & B1 & B2 & A1 & A2 \\
\hline Farinha de Trigo & $100 \%$ & $100 \%$ & $100 \%$ & $100 \%$ & $100 \%$ \\
Água* & $58-62 \%$ & $58-62 \%$ & $58-62 \%$ & $58-62 \%$ & $58-62 \%$ \\
Gordura Vegetal & $10 \%$ & $10 \%$ & $10 \%$ & $10 \%$ & $10 \%$ \\
Hidrogenada & & & & & \\
Açúcar Refinado & $5 \%$ & $5 \%$ & $5 \%$ & $5 \%$ & $5 \%$ \\
Fermento Biológico & $3,3 \%$ & $3,3 \%$ & $3,3 \%$ & $3,3 \%$ & $3,3 \%$ \\
Polidextrose & - & $5 \%$ & $10 \%$ & $5 \%$ & $10 \%$ \\
Brócolis em pó & - & $5 \%$ & $10 \%$ & - & - \\
Açaí em pó & - & - & - & $5 \%$ & $10 \%$ \\
\hline
\end{tabular}

* Com base no percentual de absorção de água de cada farinha.

\subsection{Processamento dos Pães Tipo Forma}

Os ingredientes foram pesados em balança semi-analítica separadamente. Aplicou-se o método direto, onde todos os ingredientes são colocados simlutaneamente no início da etapa de mistura, com exceção do sal e água. Eles foram misturados em misturadora de escala semiindustrial durante 1 minuto em baixa velocidade para a homogeneização dos ingredientes, em seguida foi adicionada a água e misturada por 3 minutos em velocidade média, por último foi adicionado o sal e a massa foi misturada em alta velocidade por 6 minutos até o seu completo desenvolvimento. As massas foram divididas em porções de $250 \mathrm{~g}$ e moldadas na forma de elipses manualmente. Após a moldagem manual na forma de elipses, as massas foram inseridas em sacos de polietileno de forma individual e acomodadas em Freezer Horizontal Esmaltec ${ }^{\circledR}$ para serem congeladas e permanecerem estocadas até a sua utilização. A temperatura de armazenamento foi de $-15^{\circ} \mathrm{C}$ durante 60 dias. As massas congeladas, quando completados os tempos para realização das análises, foram removidos do freezer e desembaladas. Foram colocadas sobre bandejas de alumínio e o descongelamento ocorreu em estufa de circulação forçada de ar a $30{ }^{\circ} \mathrm{C} \pm 2{ }^{\circ} \mathrm{C}$ durante duas horas. A fermentação ocorreu a $28{ }^{\circ} \mathrm{C} \pm 2{ }^{\circ} \mathrm{C}$ e $60 \%$ de umidade relativa durante duas horas. Após este processo, os pães foram forneados sem vapor a $220^{\circ} \mathrm{C}$ durante 20 minutos e resfriados à temperatura ambiente.

\subsection{Avaliação Física das Massas e dos Pães Tipo Forma}

Determinação das curvas de congelamento: Foram obtidas curvas de temperatura durante o congelamento e armazenamento congelado das massas durante 24 horas através de termopares "Tipo $\mathrm{T}$ " inseridos no centro geométrico e nas extremidades da massa de pão. $\mathrm{O}$ sistema de monitoramento e armazenamento de dados utilizado foi o Data Logger® da empresa NOVUS. 
Determinação de células viáveis de levedura: A determinação de células viáveis de levedura foi executada de acordo com metodologia mencionada por Downes e Ito (2001). Utilizou-se massas de aproximadamente 25 gramas que foram homogeneizadas em erlenmeyers contendo $225 \mathrm{~mL}$ de água peptonada $0,1 \%$, realizando-se diluições até $10^{-6}$. As diluições foram inoculadas através de espalhamento em placas de Petri contendo meio Ágar Sabouraud (2\% glicose, $2 \%$ ágar, $1 \%$ peptona, $0,05 \%$ cloranfenicol), as placas foram incubadas em estufas à $30^{\circ} \mathrm{C}$ pelo período de 03 dias. Após este período foi realizada a contagem das placas e o valor calculado com base no peso da amostra de massa, sendo os resultados expressos em Unidades Formadoras de Colônia por grama de massa (UFC/g).

\subsection{Análise Estatística}

A avaliação dos resultados dos resultados das células viáveis de levedura foi realizado o teste de médias ao nível de 5\% de significância. A análise foi realizada através do programa STATISTICA 7.0.

\subsection{RESULTADOS E DISCUSSÃO}

A figura 1 apresenta a curva de congelamento da massa padrão, sem a incorporação dos ingredientes funcionais.

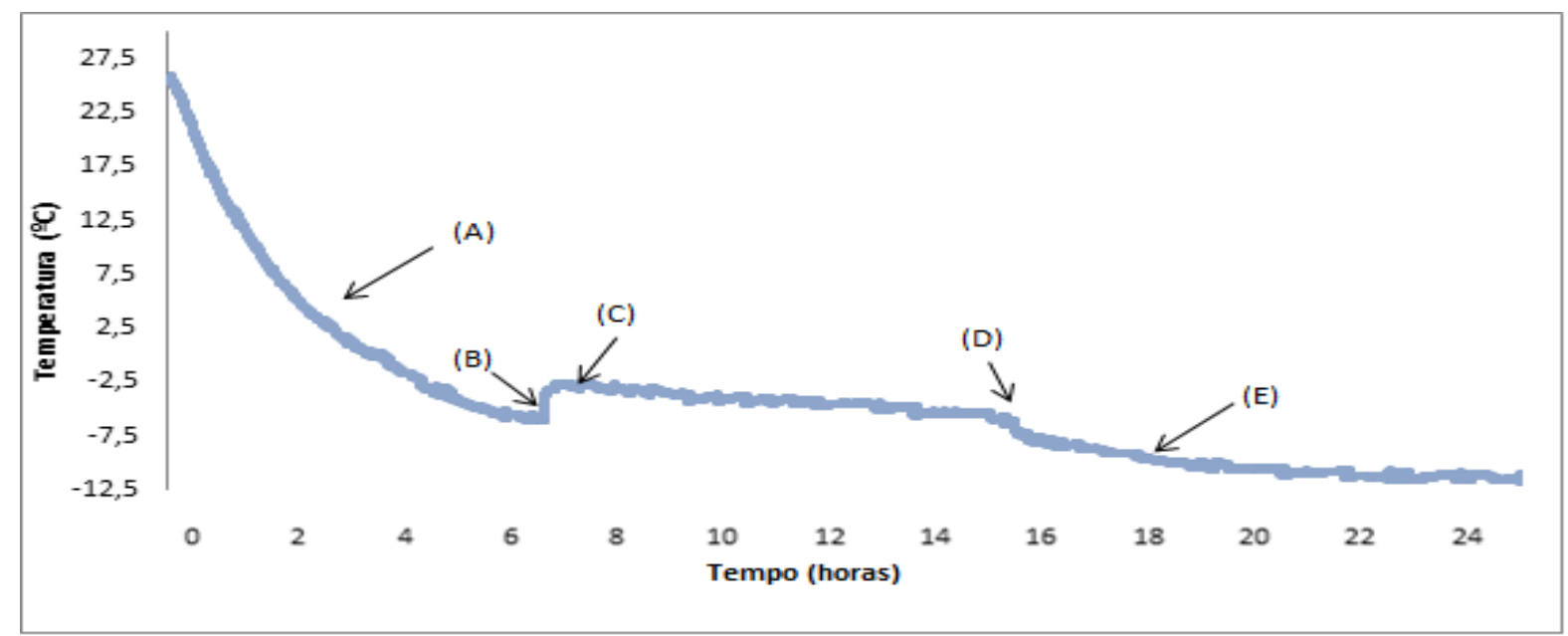

Figura 1 - Curva de congelamento da massa padrão

As massas para a produção de pães padrão entraram no freezer com temperatura média de $25,8 \pm 0,65{ }^{\circ} \mathrm{C}$ e tiveram a sua temperatura reduzida, pela retirada do calor sensídel (de A até B), que é momento início da formação da formação dos cristais de gelo, fenômeno conhecido como nucleação (B). Para as massas padrão, a nucleação ocorreu em - 6,0 $00,54{ }^{\circ} \mathrm{C}$, com a característica de subresfriamento da água. De modo instantâneo houve a liberação do calor latente de fusão (B-C), a taxa de liberação deste calor foi maior que a de resfriamento, elevando a temperatura da massa até valores próximos de $-2,8 \pm 0,88{ }^{\circ} \mathrm{C}$. De acordo com Hindmarsh et al. (2004) nesta etapa ocorre a recalescência, havendo um rápido aumento na formação de cristais de gelo impulsionados pelo subresfriamento, sendo observado entre os pontos $\mathrm{C}$ e $\mathrm{D}$, devido ao alto teor de água das massas (aproximadamente 46\%), esta etapa teve longa duração. No ponto E ocorreu a etapa de resfriamento ou têmpera, quando a temperatura 
do centro das massas foi reduzida até $-11,5^{\circ} \mathrm{C}$, quando cessou a captação dos dados de temperatura após 24 horas.

A figura 2 apresenta a curva de congelamento das massas para a produção de pães Brócolis 1 (vermelho) e Brócolis 2 (azul).

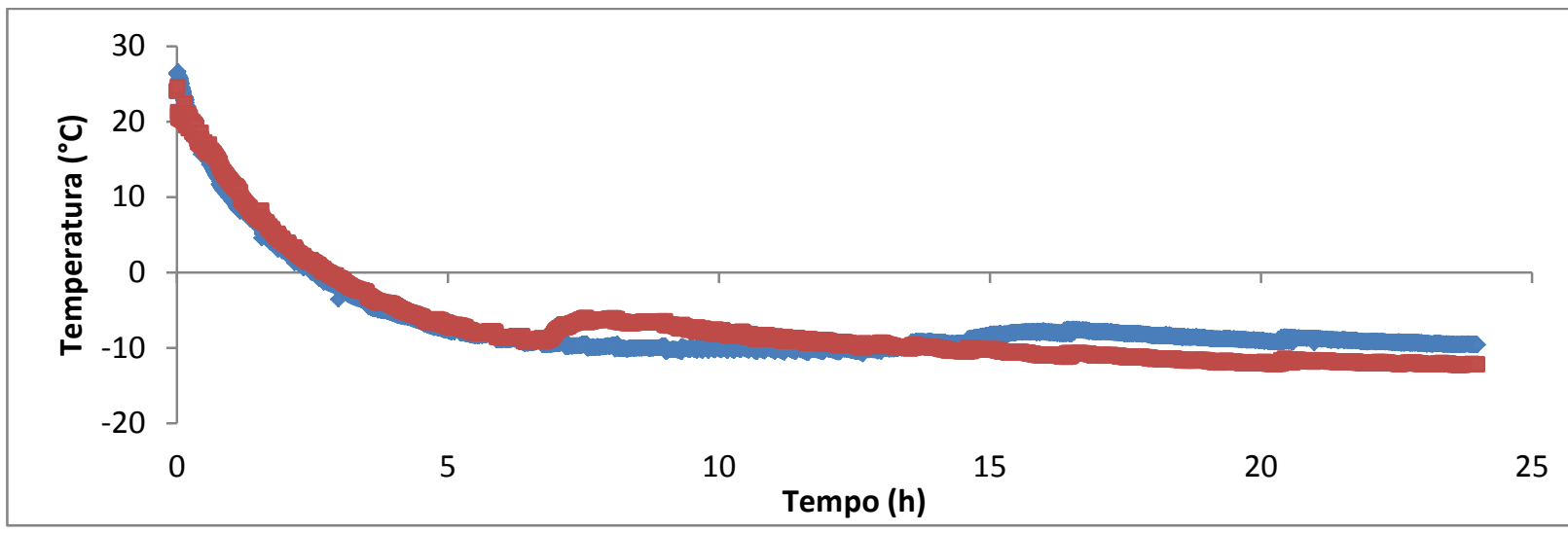

Figura 2 - Curvas de congelamento de massas Brócolis (vermelho) 1 e 2 (azul)

A temperatura inicial das massas foi de $24,06{ }^{\circ} \mathrm{C} \pm 0,33$ para a massa Brócolis 1 e 26,35 ${ }^{\circ} \mathrm{C} \pm 0,21$ para a Brócolis 2. O início da formação dos critais de gelo ocorreu após 6 horas, a uma temperatura média de $-6,51{ }^{\circ} \mathrm{C} \pm 0,27$, enquanto que para a Brócolis 2 este fenômeno ocorreu somente após 13 horas, devido à incorporação de maiores quantidades de polidextrose e brócolis em pó, o ponto de congelamento desta massa foi reduzido para temperaturas inferiores a $-10{ }^{\circ} \mathrm{C}$, o que mostra que quanto maior o teor de sólidos presentes no alimento, mais baixo será seu ponto de congelamento incipiente.

Massas produzidas com farinha de trigo e submetidas ao congelamento são constituídas de uma fase de gelo, bem como uma fase descongelada com ponto de congelamento baixo, este baixo ponto é atribuído a concentração de solutos na fase descongelada quando a água é imobilizada pela formação dos critais de gelo, é nesta fase, que, segundo Ribotta e Le Bail (2007), onde ocorrem as deteriorações, mesmo em baixa temperatura. O fluxo de calor da frente de congelamento diminui conforme a frente penetra no produto. Este fato se deve ao aumento da resistência térmica da parte congelada localizada entre a superfície refrigerada e a frente de congelamento.

No caso de geometrias cilíndricas e elipses, a resistência térmica aumenta enquanto as camadas de gelo são formadas, o volume a ser congelado é cada vez menor conforme a frente de congelamento aumenta quando se afasta da superfície (Chevalier et al., 2000), o que explica o rápido decréscimo da temperatura das massas nas primeiras horas de congelamento e a retomada de forma lenta da redução da temperatura após a liberação do calor latente de solidificação.

A figura 4 apresenta os valores de temperatura em função do tempo de congelamento das massas para a produção de pães Açaí 1 (vermelho) e Açaí 2 (azul). 


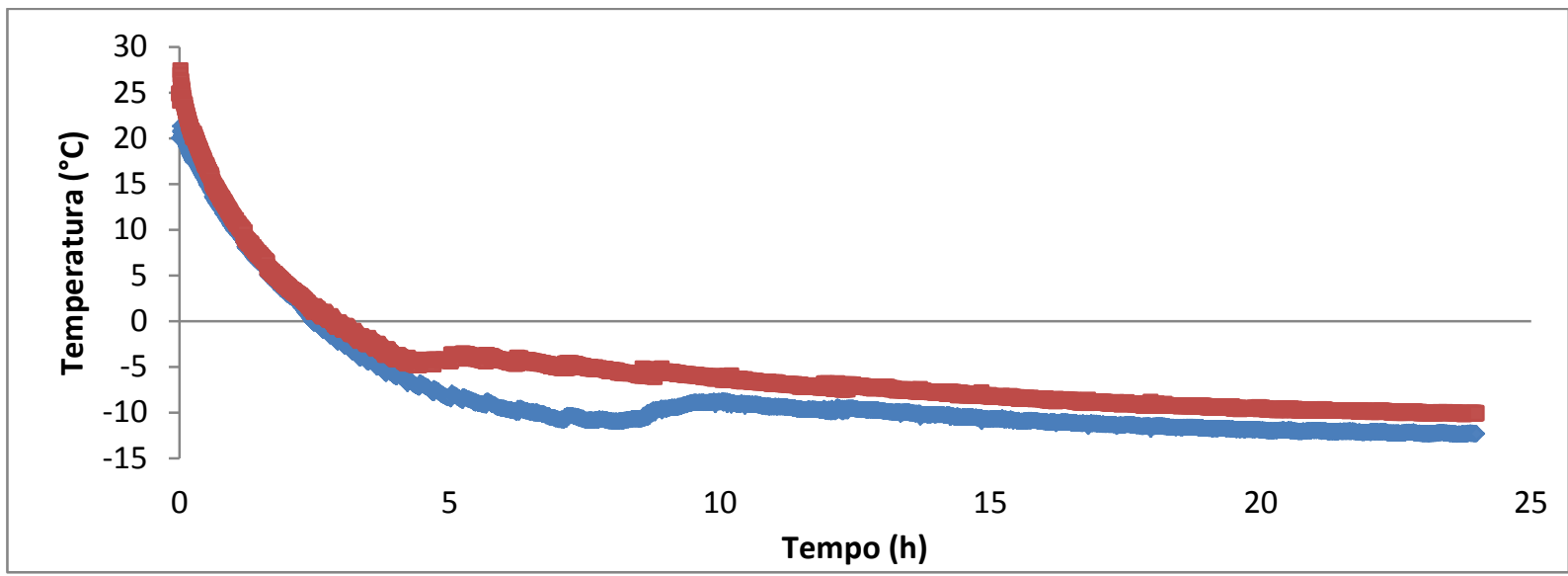

Figura 3 - Curvas de congelamento de massas Açaí 1 (vermelho) e 2 (azul).

A temperatura inicial das massas foi de $26,59{ }^{\circ} \mathrm{C} \pm 0,13$ (Açaí 1) e $20,04{ }^{\circ} \mathrm{C} \pm 0,17$ (Açaí 2). Para a massa açaí 1 , o ínicio da nucleação ocorreu após 4 horas, onde a retirada do calor sensível (A), o ínicio da formação dos cristais de gelo (B) ocorreu a temperatura de - 4,23 ${ }^{\circ} \mathrm{C} \pm 0,23$, houve o aumento da temperatura para valores de $-3,39{ }^{\circ} \mathrm{C} \pm 0,15$. Após 24 horas de coleta dos dados, a temperatura final da massa foi de - $11,26{ }^{\circ} \mathrm{C} \pm 0,17$. Pelo aumento no conteúdo de sólidos incorporados na massa Açaí 2, o ínicio da formação dos critais de gelo ocorreu apenas após sete horas (B), havendo diminuição do ponto de congelamento da massa, quando comparado com a Açaí 1, esta diferença fica evidente ao ser observada na figura 3 . $\mathrm{O}$ início da nucleação ocorreu à temperatura média de $-10,75^{\circ} \mathrm{C} \pm 0,37(\mathrm{~B})$, seguido de elevação da temperatura pela liberação do calor latente de solidificação para temperatura de - 8,83 ${ }^{\circ} \mathrm{C} \pm 0,22$. A temperatura final das massas foi de $-12,44{ }^{\circ} \mathrm{C} \pm 0,25$. Pela quantidade de soluto incorporada nas formulações e devido à capacidade de redução da temperatura do equipamento utilizado, não foi possível observar a nucleação dos solutos presentes, onde pode-se afirmar que a formação dos critais de gelo não foi total.

A tabela 2 fornece o número de células de levedura das massas congeladas por até 60 dias e os resultados a cerca do teste de tukey.

Tabela 2 - Número remanescente de células viáveis de levedura nas massas.

\begin{tabular}{cccccc}
\hline Formulação & 0 dia & 15 dias & 30 dias & 45 dias & 60 dias \\
\hline Padrão & $133^{\mathrm{Ac}} \pm 5,50$ & $53^{\mathrm{Bc}} \pm 8,50$ & $35^{\mathrm{Ca}} \pm 2,51$ & $24^{\mathrm{CDa}} \pm 4,04$ & $15^{\mathrm{Da}} \pm 2,08$ \\
B1 & $136^{\mathrm{Ac}} \pm 4,16$ & $115^{\mathrm{Bde}} \pm 1,73$ & $80^{\mathrm{Cd}} \pm 3,78$ & $69^{\mathrm{CDde}} \pm 3,32$ & $55^{\mathrm{Dc}} \pm 2,02$ \\
B2 & $132^{\mathrm{Ac}} \pm 4,16$ & $117^{\mathrm{Bde}} \pm 2,00$ & $89^{\mathrm{Cd}} \pm 4,04$ & $70^{\mathrm{Dde}} \pm 4,35$ & $66^{\mathrm{Dd}} \pm 3,21$ \\
A1 & $141^{\mathrm{Ab}} \pm 2,00$ & $121^{\mathrm{Bd}} \pm 3,05$ & $92^{\mathrm{Ccd}} \pm 3,21$ & $77^{\mathrm{Dd}} \pm 3,51$ & $68^{\mathrm{Ed}} \pm 1,52$ \\
A2 & $139^{\mathrm{Ab}} \pm 1,52$ & $127^{\mathrm{Ba}} \pm 3,05$ & $101^{\mathrm{Cc}} \pm 2,08$ & $87^{\mathrm{Dc}} \pm 3,21$ & $71^{\mathrm{Ed}} \pm 5,29$ \\
\hline
\end{tabular}

*Valores médios obtidos a partir da diluição de $10^{-4}$ e três repetições; **Resultados expressos em $10^{5}$ UFC/g de massa. ${ }^{1}$ Letras minúsculas diferentes em uma mesma coluna e letras maiúsculas diferentes em uma mesma linha não apresentam diferenças significativas ao nível de 5\% de significância.

A maior contagem de células viáveis de levedura em massas não-congeladas (tempo zero) foi apresentada pela formulação A2, com $139 \times 10^{5}$ células. As formulações adicionadas de brócolis (B1 e B2), T1 e Padrão não diferiram entre si, ao nível de 5\% de significância, o mesmo ocorreu entre as formulações A1 e A2. Ao $15^{\circ}$ dia de armazenamento congelado, a formulação que apresentou a maior redução na viabilidade das leveduras foi a padrão. A 
menor redução ocorreu na formulação A2. Não houve diferenças estatísticas entre T2, B1 e $\mathrm{B} 2$, as demais amostras diferiram entre si.

Decorridos 30 dias de armazenamento congelado das massas, a formulação B1 obteve a maior redução na viabilidade celular, seguido da formulação A1. As formulações T2 e A2 não diferiram entre si ao nível de significância de 5\%, bem como as formulações adicionadas de brócolis (B1 e B2). Para 45 dias de armazenamento congelado, a formulação B2 apresentou a maior redução de viabilidade celular de leveduras neste período, seguido da T1 e T2. Houve diferenças significativas entre todas as formulações, com exceção entre B1 e B2. Após 60 dias, o menor valor de células viáveis de levedura foi apresentado pela formulação padrão ( $15 \times 10^{5}$ células), a maior redução foi observada em A2. Apenas as formulações B2, A1 e A2 não diferiram entre si, ao nível de $5 \%$ de significância.

De acordo com Massaguer (2006), após o congelamento, durante a estocagem congelada, a destruição continua, a taxa de morte durante o período de armazenamento pode ser maior no início e geralmente decresce com o tempo, o que se aplicou às formulações de pães desenvolvidas neste estudo, onde as maiores reduções de células viáveis foram entre os trinta primeiros dias de armazenamento congelado.

A tabela 3 apresenta o percentual de células viáveis ao longo do tempo de armazenamento congelado.

Tabela 3 - Percentual de células viáveis de levedura nas massas

\begin{tabular}{cccccc}
\hline $\begin{array}{c}\text { Dias de armazenamento } \\
\text { congelado }\end{array}$ & Padrão & B1 & B2 & A1 & A2 \\
\hline $\mathbf{0}$ & $100 \%$ & $100 \%$ & $100 \%$ & $100 \%$ & $100 \%$ \\
$\mathbf{1 5}$ & $39,84 \%$ & $84,55 \%$ & $88,63 \%$ & $85,81 \%$ & $91,36 \%$ \\
$\mathbf{3 0}$ & $26,31 \%$ & $58,82 \%$ & $67,42 \%$ & $65,24 \%$ & $72,66 \%$ \\
$\mathbf{4 5}$ & $18,04 \%$ & $50,73 \%$ & $53,03 \%$ & $54,60 \%$ & $62,58 \%$ \\
$\mathbf{6 0}$ & $11,27 \%$ & $40,44 \%$ & $50,00 \%$ & $48,22 \%$ & $51,07 \%$ \\
\hline
\end{tabular}

Padrão: formulação sem a adição dos ingredientes funcionais; Açaí 1 (A1): $5 \%$ de açaí em pó e polidextrose; Açaí 2 (A2): $10 \%$ de açaí em pó e polidextrose; Brócolis 1 (B1): $5 \%$ de brócolis e polidextrose; Brócolis 2 (B2): 10\% de brócolis em pó e polidextrose; Tomate 1 (T1): $5 \%$ de tomate em pó e polidextrose; Tomate 2 (T2): 10\% de tomate em pó e polidextrose.

Comercialmente, pode ser observado que, com uma redução de $50 \%$ das células de levedura viáveis, os pães não apresentam o mesmo desempenho na fermentação (Kechinski et al., 2010).

Até o $15^{\circ}$ dia de armazenamento congelado a formulação padrão apresentou redução de $60 \%$ da viabialidade das células de levedura; $13,53 \%$ entre o $15^{\circ}$ e o $30^{\circ}$ dia; $8,27 \%$ entre o $30^{\circ}$ e $45^{\circ}$ e apenas $6,77 \%$ até o $60^{\circ}$ dia. Comportamento semelhante foi obtido pela formulação T1, onde o maior percentual de morte de células de levedura concentrou-se até o $15^{\circ}$ dia. Para a formulação T2 as maiores perdas de células viáveis ocorreram entre o $15^{\circ}$ e $30^{\circ}$ dia de armazenamento congelado, bem como entre os dias 45 e 60. Com relação as formulações adicionadas de polidextrose e brócolis em pó, para B1, a maior redução entre os trinta primeiros dias, com $15,45 \%$ e $25,75 \%$, respectivamente, B2 obteve o mesmo comportamento, entretanto, com menores reduções, de $11,37 \%$ para os primeiros quinze dias 
e de $21,21 \%$ entre o $15^{\circ}$ e $30^{\circ}$ dia. A adição de $10 \%$ de polidextrose e brócolis em pó promoveu menores reduções de viabilidade celular ao longo de 60 dias de armazenamento congelado, preservando $50 \%$ do valor inicial das células de levedura, contra $11,27 \%$ da formulação padrão, demonstrando efeito crioprotetor.

Comportamento semelhante foi observado para as formulações adicionadas de polidextrose e açaí em pó, onde as maiores reduções de viabilidade celular foram observadas entre os trinta primeiros dias, para A1 e para a A2, entre o $30^{\circ}$ e $45^{\circ}$ dia, ao final do período estudado as formulações preservaram valores superiores a $48 \%$ das células viáveis, também demonstrando que o açaí possui efeito crioprotetor.

A formação de gelo dentro das células das leveduras é o fator principal responsável pela morte celular, quanto menor a formação destes cristais intracelulares, maior é a viabilidade das leveduras, conforme relatam Zhang et al. (2007). O conteúdo intracelular das leveduras, quando exudados, promove colapsos nas proteínas do glúten, sendo um fator de enfraquecimento além do congelamento.

Jia et al. (2012), verificaram que a intensidade da solubilidade das proteínas do glúten foi maior quando houve menor redução da viabilidade celular das leveduras. Meziani et al. (2012) afirmam que a taxa de congelamento lento, a qual foi empregada neste estudo, tem influência direta sobre a manutenção de equilíbrio osmótico na membrana da célula de levedura durante o congelamento, a cinética de transferência de água do meio intracelular para o extrecelular foi favorecido por osmose.

O conteúdo celular externo se transforma em hipertônico devido a desidratação e a formação dos cristais de gelo, fazendo com que a célula perca água e tenha influência sobre a sobrevivência celular (Chua e Chou, 2009). O lançamento de líquido intracelular provocado pelas condições externas adversas às células do fermento promovem a desidratação e plasmólise.

Pode-se afirmar que a adição dos ingredientes funcionais promoveram um equilíbrio osmótico entre o meio e as células de levedura, agindo como crioprotetores, minimizando os danos ao longo do tempo de armazenamento congelado. Estes resultados são de grande importância visando à manutenção da qualidade das massas e consequentemente dos pães após 60 dias de armazenamento congelado, tendo em vista que as leveduras e seu respectivo processo de fermentação são responsáveis pelo desenvolvimento da expansão da massa, volume dos pães, porosidade do miolo e de alguns componentes de sabor e aroma dos pães.

\subsection{CONCLUSÃO}

A incorporação dos ingredientes funcionais em formulações de pães tipo forma reduziu o ponto de congelamento das massas quando comparados à formulação padrão, onde o congelamento foi mais lento e em temperaturas mais baixas, devido a isto, houve alterações na viabilidade celular das leveduras, após 60 dias, foi possível a manutenção de $51,07 \%$ das células na formulação A2 e 50,00\% em B2, superiores à padrão, que obteve apenas 11,27\%. 


\subsection{REREFENNCIAS}

DOWNES, F. P.; ITO, K. Compendium of methods for the microbiological examination of foods. Washington: American Public Heath Association, 2001. 676 p.

CHEVALIER, D.; LE BAIL, A.; GHOUL, M. Freezing and ice crystals formed in a cylindrical food model: part I. Freezing at atmospheric pressure. J. Food Eng., v. 46, n. 4, p. 277-285, 2000.

CHUA, K. J.; CHOU, S. K. On the study of the freeze-thaw thermal process of a biological system. Appl. Therm. Eng., v. 29, n. 17, p. 3696-3709, 2009.

HINDMARSH, J. P.; RUSSELL, A. B.; CHEN, X. D. Experimental and numerical analysis of the temperature transition of a freezing food solution droplet Chem. Eng. Sci., v. 59, n. 12, p. 2503-2515, 2004.

JIA, C.; HUANG, W.; WU, C.; LV, X.; RAYAS-DUARTE, P.; ZHANG, L. Characterization and yeast crioprotective performance for thermostable ice-structuring proteins from Chinese Privet (Ligustrum vulgare) leaves. Food Res. Int., v. 49, n. 1, p. 280-284, 2012.

KECHINSKI, C. P.; CASTRO, M. G.; FLECK, R. J.; NOREÑA, C. Z. Viabilidade de células de levedura em massas congeladas de pão francês. Ciência Rural, v. 40, n. 5, p. 1193-1198, 2010 .

MASSAGUER, P.R. Microbiologia dos Processos Alimentares. São Paulo: Varela, 2006, 258p.

MEZIANI, S.; JASNIEWSKI, J.; RIBOTTA, P. D.; ARAB-TEHRANY, E.; GHOUL, J. M. M.; DESOBRY, S. Influence of yeast and frozen storage on rheological, structural and microbial quality of frozen sweet dough. J. Food Eng., v.109, p. 538-544, 2012.

RIBOTTA, P. D.; LE BAIL, A. Effect of additives on the thermo-mechanical behavior of dough systems at sub-freezing temperatures. Eur. Food. Res. Technol., v. 224, n. 1, p. 519524, 2007.

RIBOTTA, P. D.; PÉREZ, G. T.; AÑÓN, M. C.; LEÓN, A. E. Optimization of additive combination for improved soy-wheat bread quality. Food Biop. Technol.. v. 3, n. 2, p. 395405, 2008.

SHI, K.; YU, H.; JIN, J.; LEE, T. Improvement to baking quality of frozen bread dough by novel zein-based ice nucleations film. J. Cereal Sci., v. 57, n. 3, p. 430-436, 2013.

ZHANG, C.; ZHANG, H.; WANG, L. Effect of carrot (Daucus carota) antifreeze proteins on the fermentation capacity of frozen dough. Food Res. Int., v. 40, n. 6, p. 763-769, 2007. 